\title{
College of Education Pre-Service Teachers' Attitude in Terms of Usefulness, Confidence and Enjoyment towards Geometry by Gender
}

\author{
Anas Seidu Salifu ${ }^{1 *}$ (), Michael Johnson Nabie ${ }^{2}$ (), Jones Apawu ${ }^{2}$ (1)
}

${ }^{1}$ Senior Tutor, Department of Mathematics \& ICT, E.P. College of Education, Bimbilla, GHANA

${ }^{2}$ Department of Mathematics Education, University of Education, Winneba, GHANA

${ }^{*}$ Corresponding Author: salifuanas@gmail.com

Citation: Salifu, A. S., Nabie, M. J., \& Apawu, J. (2021). College of Education Pre-Service Teachers' Attitude in Terms of Usefulness, Confidence and Enjoyment towards Geometry by Gender. Contemporary Mathematics and Science Education, 2(2), ep21012. https://doi.org/10.30935/conmaths /11110

\begin{abstract}
This study investigated gender differences in pre-service teachers' attitude towards geometry in Northern Region of Ghana. The research design was descriptive cross-sectional survey. A concurrent mixed-methods approach was adopted using both closed and open-ended questionnaire items. The population for the study was one thousand, six hundred and sixty-nine (1669) level 200 Pre-service Teachers (PSTs). The sample composed of two hundred and forty (240), comprising 120 PSTs each of female and male. The sampling procedure was convenient, stratified and simple random. The instrument used was 32 item Utley Geometry Attitude Scales (UGAS) that was developed by Utley (2007) and 4 opened ended questions. Statistically significant difference was detected between the male and female in their responses to usefulness of learning geometry, confidence to learning geometry and enjoyment of learning geometry which all favored the male PSTs who showed positive attitude towards geometry.
\end{abstract}

Keywords: attitude, geometry, gender differences, usefulness, confidence, enjoyment, College of Education (CoE), Pre-service Teachers (PSTs)

Received: 12 Jan. 2021 Accepted: 9 Jun. 2021

\section{INTRODUCTION}

The geometry course in the Colleges of Education in Ghana is specifically designed to develop and consolidate the basic mathematical knowledge and skill of pre-service teachers (PSTs). The goal of the geometry course in Colleges of Education is divided into three (3) parts: (a) to extend the mathematical knowledge and skills of pre-service teachers in geometry to a level significantly beyond what they are likely to teach in basic school mathematics curriculum, (b) to provide preservice teachers with a general understanding of the basic principles of teaching basic school mathematics and (c) to support pre-service teachers to develop appropriate practical approaches to teaching and assessment. The geometry course in the Colleges of Education in Ghana places more emphasis on recognizing the uses of mathematics in different local and global contexts as well as exploring learners' misconceptions and difficulties in geometry.

In order to reverse the appalling poor performance and challenges of pre-service teachers in geometry over the years, the 2018 new curriculum has provided the following methods of delivery geometry course lessons: face to face, practical activity, work-based learning, seminars, independent study and E-learning. These modes of deliveries seek to achieve the aims of the new curriculum which are to instill in new teachers the nation's core value of honesty, integrity, creativity and responsible citizenship and to achieve inclusive, equitable, high-quality education for all learners in line with sustainable Development Goal (SDG) four.

Many researchers (Hannafin, 2004; Hannafin et al., 2008; Kaufmann \& Schmalstieg, 2003) have argued that Geometric conceptions is regarded as a base for learning mathematics. Geometry helps PSTs to develop cognitive skills, such as investigation, researching, criticizing, creative thinking, illustrating what they have learnt, and self-expression (Erdogan et al., 2009; Mistretta, 2000). Additionally, geometry is essential in our daily life and various professions because the concepts of shapes and objects learnt are also available in our world (Goos \& Spencer, 2003). The solving of everyday problems enables students to develop the skills of visualization, critical thinking, intuition, perspective, problem-solving, conjecturing, deductive reasoning, logical argument and proof which supports Armah, Cofie, and Okpoti's (2017) study. Attitudes towards geometry are the important determinants of academic success and achievement. In order to succeed in geometry, positive attitude is a prerequisite. In the course of teaching and learning process attitudes are wellestablished structures of positive or negative assessment, enthusiastic emotion and dispositions to social objects (Knezek \& Christensen, 
2018). Also, Awofala, Arigbabu, and Awofala (2013) stated that "attitude recognizes three main components in an attempt to define it thus: emotional response, beliefs regarding mathematics, and behaviour related to mathematics" (p. 2). From studies (Guner, 2012; Tapia \& Marsh, 2004; Zan \& Di Martino, 2007), it is evident that, attitude towards geometry plays an important role in determining achievement in geometry. PSTs with positive attitude towards geometry will invariably attain high marks in geometry achievement. Winter and O'Raw (2010) opined that, the construct attitude is more stable than emotions and feelings. Again, Winter and O'Raw (2010) said attitude is malleable and has influence on partaking, because attitudes are formed in response to teaching practices, curriculum, and organizational arrangements.

Wigfield and Eccles (2002) defined usefulness as "how a task fits into an individual's future plans, for instance, taking a math class to fulfill a requirement for a science degree" (p. 95). Adelson and McCoach (2011) explained perceived usefulness as students' perception of everyday life and future significance of mathematics. PSTs attitude towards mathematics depends on the perceived usefulness. Syyeda (2016) stressed that if PSTs see the significance of mathematics in real life situations they will be motivated to study, practice, and learn it. Usefulness of mathematics is a positive predictor of success in the subject. Certainly, PSTs have a greater prospect to apply and use some geometry topics they learnt in their daily life. Young-Loveridge et al. (2006) elaborated that, PSTs consider usefulness of mathematics as a decisive factor for their daily life and future career formation. Kadijevich (2006) posits that, mathematical attitudes are frequently saturated by either usefulness of mathematics or by self-confidence in mathematics. Therefore, in most mathematics curricula across the globe, it is stressed that PSTs should be mindful of the usefulness of mathematics and geometry (National Council of Teachers of Mathematics [NCTM], 1989).

According to Cambridge Advanced Learners' Dictionary Third Edition, confidence is the quality of being certain of your abilities or of having trust in people, plans, or the future. Ball, (1990) asserts that preservice secondary mathematics teachers begin their education programs with some prerequisite knowledge in education thus boosting their confidence in teaching. On the other hand, extensive pre-service teachers' mathematical preparation in colleges may not lead to more confidence if that preparation is uncompleted. $\mathrm{Li}$ and Kulm (2008) opine that pre-service teacher's confidence to learn mathematics and knowing what to teach are both important. Adelson and McCoach (2011) explained self-confidence in geometry as one's own beliefs and capability to learn and achieve good results in geometry. Confidence is significant in geometry since it makes PSTs sure of themselves when solving non routine problems and learning new concepts. Confidence also affects PSTs' enjoyment and interest in geometry; therefore, getting them more involved in geometry tasks (Hart \& Walker, 1993). Selfconfidence is one of the attitudinal variables found to influence PSTs' participation and achievement in geometry (Hannula et al., 2004). According to Van der Bergh (2013), overcoming PSTs fear of failing and been successful in learning geometry depends on their high selfconfidence on beliefs. Invariably, PSTs with high self-confidence are ready to take geometrical challenges which results in an increase in their academic achievement. Likewise, PSTs with low self-confidence do not believe in themselves hence avoids taking geometry tasks (Adelson \& McCoach, 2011).
According to Cavallo and Laubach (2001), enjoyment in geometry refers to the cheerfulness or happiness learners feel resulting from their experiences in geometry. Also, Pekrun (2006) indicated that, enjoyment as an emotional state emanates from engaging in activities a person value and find interesting and or have control over. Stipek (2002) stated that enjoyment refers to how much students liked working on geometry task and how boring they found geometry to be. Stipek (2002) stressed that, enjoyment and positive emotions foster behaviors that enhance learning. According to Kupari and Nissinen (2013), the extent to which PSTs enjoy doing and learning geometry is referred to as enjoyment of geometry. Syyeda (2016) study posits that, behaviour or cognitive aspect of Pre-service Teachers' attitude can influence PSTs enjoyment while learning geometry. OECD (2013) indicated from PISA that learners study geometry because they find it enjoyable and interesting. The report went further to posit that the degree and continuity of engagement in learning and the depth of understanding depends on both interest and enjoyment. Invariably, the more PSTs enjoy doing geometry, the more the likelihood that they will involve themselves in problem-solving which will improve their learning and achievement. Since learning of geometry and achievement are interconnected, it is important to assess students' viewpoints on enjoyment of geometry in order to make a decision on PSTs' learning and achievement. In a study by Frenzel, Fiedler, Marx, Reck and Pekrun (2020) in which 244 secondary school teachers were used as sample, revealed that teachers who perceived their relationships with their students has higher quality, and to a lesser extent those who perceived their students as more motivated enjoyed the teaching. In a similar study by Marbán, Palacios, and Maroto (2020) in which they concentrated on pre-service primary school teachers in Spain revealed that a high level of self-concept in mathematics and a low level of anxiety in mathematics were strongly correlated to the enjoyment of doing mathematics, which in turn predicted the enjoyment of teaching mathematics. Russo and Russo (2019) stressed that teachers can enhance their enjoyment of teaching mathematics if they are autonomous, and investigating or exploring mathematics concepts through inquiry-based topic areas, which are of interest to them and their students. In a similar vein, Russo, Bobis, Downton, Feng, Hughes, Livy, McCormick, and Sullivan (2020) study which used a sample of 10 early-year primary school teachers indicates negative-to-positive turning point experiences of the most responses by the high-enjoyment primary school teachers. The study also revealed that respondents had consistent positive feelings towards mathematics throughout their entire lives.

Mato and De La Torre (2010) results were confirmed in wider research, concerning geometry study attitude among the secondary school students. Their study showed that students with better academic performance have more positive attitude towards geometry than those with poorer academic performance. Mata et al. (2012) argue that, a positive attitude towards geometry reflects a positive emotional disposition, a negative attitude towards geometry relates to a negative emotional disposition. Atanasova-Pachemska et al. (2015) study also supported Mata et al. (2012) finding by an assertion that positive attitude towards geometry reflects a positive self-confidence, enjoyment, value and emotional disposition likewise a negative attitude towards geometry relates to a negative self-confidence, value, enjoyment and emotional disposition. Furthermore, Mata et al. (2012) indicated that one is expected to achieve better results in a subject that one enjoys, has confidence in or finds useful because these attitude dispositions have an impact on an individual's behaviour in real life. 
Mata et al. (2012) went further to propose that positive attitudes towards geometry are anticipated because they may influence one's readiness to learn and also the benefits one can derive from geometry teaching. Özgün-Koca and Şen (2006), and Taşdemir (2009) revealed that the negative attitude towards geometry increased when the grade levels increased. Mensah et al. (2013) study used a sample of 100 students and 4 teachers, and reported a significant relationship between teacher attitude and student attitude toward geometry. It also revealed that teachers' positive attitude radiated confidence in students, hence made them develop positive attitude towards the learning of geometry. Simegn and Asfaw (2018) study used a sample of 367 comprising of 240 grade 10 students and 127 grade 12, with stratified random sampling technique. The aim of their study examined the effect of students' attitude towards geometry on the achievement of female and their male counterparts. The results obtained from both grade levels, unveiled that students had positive attitude towards geometry but at medium level, however, the level of female students was less than males. Sunzuma et al. (2013) study explored secondary school student's attitudes towards their learning of geometry. The study revealed that the students' attitude towards the usefulness of geometry was positive and that many of them believed that geometry is a valuable and necessary topic/area which can help them in their future career. The result also showed that the majority $(80 \%)$ of the students did not like solving geometrical problems. It also emerged that geometry is not a difficult topic to both male and female students and that though most students did not like solving geometry questions; they considered geometry to be useful. Markovits and Patkin (2021) examined in-service preschool teachers' attitudes and beliefs about geometry teaching. Their study design was a mixed descriptive approach with thirty-four Israeli preschool teachers as the participants that investigated knowledge of shapes and solids. The results of their study indicated that majority of the participants like geometry while others indicated neutral or hate for geometry. In a similar study, Usman, Yew, and Saleh (2019) investigated the effects of van Hiele's phase-based teaching strategy and gender difference of preservice mathematics teachers' attitude towards geometry. They employed pre-test and post-test quasi-experimental design with 149 subjects. The outcome shows that the pre-service mathematics teachers' attitude towards geometry improved after the van Hiele's phase-based teaching strategy was employed. Also, Niyukuri, Nzotungicimpaye, and Ntahomvukiye (2020) examined Pre-service Teachers' experiences in learning geometry and their confidence to teaching it with convergent parallel mixed methods research. Niyukuri et al. (2020) randomly selected Ninety-seven Pre-service Teachers from two Colleges of Education in Burundi. The results of their study indicated that the teacher-centred approach was what has been used in their respective secondary schools in teaching geometry. Nevertheless, Pre-service Teachers displayed higher confidence in teaching geometry. In a study by Gresham (2017), it was revealed that the lack of confidence and anxiety are the main obstacles of pre-service teachers advancing in their courses. Gresham (2017), study also revealed that a low level of confidence results in pre-service teachers choosing to teach at a lower grade schools or classes. Gresham (2017) interviewed some mathematics teachers and reports that some of the teachers claimed they lost their confidence in the early stages of their education but got the confidence level increased after their teacher training programmes.

In comparison to the female students, Asante (2012) reported that male students are more positive towards mathematics. In similar research conducted in Ghana on sex differences in geometry among
Senior High School students, Asante (2010) found that when compared with boys, girls lacked confidence, had debilitating causal attribution patterns, perceived mathematics as a male domain, and were anxious about mathematics. This confirms the assertion that male students have more positive attitudes towards mathematics than female students. In a study by Kyei et al. (2011), results indicated that male students performed better than their female counterparts in mathematics. Kyei et al. (2011) study also indicated that girls lacked self-confidence in working mathematics problems in the Upper East Region of Ghana. Cann (2009) reported in a study that Wales's girls were more likely than boys to report feelings of anxiety and a lack of confidence in mathematics. In a study by Bae et al. (2000) on their analysis of National Assessment of Educational Progress (NAEP) revealed that females are less likely than males to think they were good at mathematics. This confirms the assertion that male students have more positive attitudes towards geometry than female students.

Tsao's (2017) study explored pre-service elementary school teachers' attitudes toward learning of geometry where 56 participants completed the Likert Scale of Utley Geometry Attitude Scales (UGAS). The UGAS subscale measured usefulness of studying geometry, confidence of learning geometry and the enjoyment of studying geometry. The study revealed that, the pre-service elementary teachers' attitudes toward the usefulness of geometry were moderately positive, and that many of them believed that geometry was a valuable and necessary topic which could help them in their future careers and education. The correlations among the three subscales were all statistically significant. There appears to be a significant relationship between usefulness of studying geometry, enjoyment of learning geometry, and confidence of learning geometry in pre-service teachers. A significant relationship $(p<0.01)$ also appears to be between selfreport grade and usefulness of studying geometry and confidence of learning geometry in pre-service teachers. Again, Tsao's (2018) work revealed that there was a statistically significant difference in mean score between the pre-and post-test. This means there was an improved attitude towards geometry when the constructivist instructional method was used. The instrument used in that study was Utley Geometry Attitude Scales (UGAS), with sub-scales of usefulness, confidence and enjoyment of studying geometry. In a quantitative methodology study, Dede (2012) examined affective variables influencing students' attitudes towards geometry as they progress from grade 8 to 11. "Enjoyment", "Usefulness" and "Anxiety" were the attitude variables in the questionnaire. The results of the study were:(a) students in general, enjoy geometry, (b) have positive attitudes towards the usefulness of geometry, (c) have, in general, high level of anxiety for geometry, and (d) statistically, there exist significant correlations amongst attitude variables according to the grade levels. Kaur (2016) study scrutinizes the achievement in geometry of ninth class government school students in relation to their attitude towards geometry. The results showed that achievement in geometry of adolescents studying in government schools has significant and positive correlation with different dimensions of self-confidence, motivation, usefulness, teacher's expectations and enjoyment as constructs attitude towards geometry. The study concluded that there is significant difference in achievement in mathematics of ninth class government school students in relation to their attitude towards mathematics.

Khun-Inkeeree et al. (2016) study found that there was no difference between gender attitudes towards geometry. Also, no gender difference was reported by Mohamed and Waheed (2011) study. 
Mohamed and Waheed (2011) indicated that PSTs' attitude towards geometry was an established factor that is recognized to influence their achievement in geometry. Karjanto (2017) quantitative study documented that there was a positive correlation between earlier high achievement in mathematics and a favourable attitude towards mathematics by preservice teachers. The study also indicated that there was no significant difference in attitudes towards mathematics when Tapia and Marsh II instrument was adopted for the data collection. Using a descriptive survey research design, Awofala (2016), sampled 316 pre-service mathematics teachers. He used Tapia's 1996 Attitudes Toward Mathematics Inventory (ATMI) to collect the data. The instrument had 40 items, some of which included; enjoyment, motivation, self-confidence, and value of mathematics. The results from this study indicate that preservice teachers' attitudes towards mathematics were positive and high. Also, Awofala's (2016) study discloses that there was no significant difference by gender, selfconfidence, enjoyment, motivation, and value of mathematics. Carroll and Gill (2012) findings indicated that most female students of the University of Limerick in Ireland who participated in the study had considerable positive attitudes towards geometry than their male counterparts in the study. On the contrary some studies emphasized that males showed more positive attitudes towards geometry than females (Michelli, 2013; Tasdemir, 2009).

This current study on pre-service teachers' attitude in terms of usefulness, enjoyment, confidence towards Geometry by gender is so important in the sense that, there are few studies in Ghana on attitudes towards Mathematics. Most of these studies were conducted in either Senior High School (SHS) or Junior High School to determine students' attitude towards Mathematics and in all cases, the studies were done in Southern Ghana. Studies did not concentrate on the usefulness, confidence and enjoyment of Geometry, but covered mathematics as a discipline. For instance, studies (Asante, 2012; Asare-Nkoom, 2007; Eshun, 2004; Nyala, 2008; Wilmot \& Otchery, 2012) were all conducted in Southern Ghana using either Senior High School or Junior High School students to investigate students' attitudes towards Mathematics. Also, Asomah, Dennis, Alhassan, and Asiedu (2018) used public and private Junior High Schools in Southern Ghana in their study which also concentrated on students' attitude towards mathematics.

Also, this study is important because there seems to be no single study on PSTs attitudes in terms of usefulness, confidence and enjoyment of Geometry in the Colleges of Education in Ghana. It is significant again because Colleges of Education in Ghana produce PSTs in Mathematics for basic schools. The PSTs studied Geometry course, hence there is the need to investigate their attitudes in terms of usefulness, confidence and enjoyment. This study also provide literature for further studies in Colleges of Education and Universities in Ghana and the world at large. This study revealed the PSTs actual attitudes towards Geometry in Colleges of Education.

\section{Statement of Problem}

Studies by the following Ghanaian researchers (Asante, 2010, 2012; Kyei et al. 2011; Nyala, 2008) have either concluded that there are gender differences or no gender differences in students' attitude towards mathematics. The gaps in their studies are that, they conducted those studies in Southern Ghana on senior high school students and generally on mathematics. This present study sort to bridge the gaps;

1. By concentrating in Northern Region of Ghana.

\section{Using geometry as the course area}

3. By involving Pre-service teachers as participants of study

Therefore, this study was fashioned to find out whether gender differences exist among pre-service teachers' attitude (usefulness, confidence and enjoyment) towards geometry.

\section{Purpose of the Study}

The purpose of the study was to investigate gender differences in pre-service teachers' attitude in terms of usefulness, confidence and enjoyment towards geometry in Northern Region Colleges of Education of Ghana.

\section{Research Questions}

In pursuance of the stated purpose, the following research questions were formulated to guide the study:

1. What are PSTs' attitudes towards usefulness of learning geometry by gender?

2. What are PSTs' attitudes towards confidence of learning by gender?

3. What are PSTs' attitudes towards enjoyment of learning geometry by gender?

\section{Research Hypotheses}

The following hypotheses were formulated to guide the study.

1. There is no significant difference between female and male PSTs attitude on usefulness of learning geometry.

2. There is no significant difference between female and male PSTs attitude on confidence of learning by gender?

3. There is no significant difference between female and male PSTs attitude on enjoyment of learning geometry by gender?

4. There is no significant difference between female and male PSTs overall (usefulness, confidence, and enjoyment of learning geometry) attitude towards geometry by gender?

\section{METHODOLOGY}

\section{Research Design}

A concurrent mixed-methods approach was adopted using both closed and opened ended questionnaire items where both quantitative and qualitative data were collected together at the same time. The research design was descriptive cross-sectional survey.

\section{Population and Sample}

The population for the study was all level 200 PSTs in the Northern Region of Ghana. The sample for the study was drawn from Evangelical Presbyterian College of Education- Bimbilla, Bagabaga College of Education and Tamale College of Education. A sample of two hundred and forty (240) PSTs comprising of 120 each of female and male was used.

\section{Sampling Procedure}

The sampling procedure was convenient, stratified and simple random. The convenient sampling method was used to select the Colleges of Education for the study. Convenient sampling was used because the researchers could easily reach out to those Colleges, the distance between them are not so wide apart. In this study, stratified 
sampling was also used to obtain the gender balance in the sample. The students were first stratified into categories or strata: by gender or sex group (male and female). The stratified sampling was used because the researchers needed to have both gender in the sample. Specifically, nonproportional stratified sampling was used to select equal number of male and female for the study. Simple random sampling technique was then used to select the pre-service teachers from the respective Colleges. In this study, computer generated simple random numbers was used to represent the index numbers of the selected PSTs.

\section{Instruments and Pilot Study}

In this study, the Utley Geometry Attitude Scales (UGAS) that was developed by Utley in 2007 was adapted. The UGAS was developed after extensive review of a variety of existing instruments used to measure attitudes towards mathematics (Utley, 2007). The entire closed ended 32 item UGAS was used to collect the data. Also, the researchers developed three (3) opened ended questions to collect qualitative data to support the quantitative data. All the three (3) opened ended questions had a yes or no option for the PSTs to tick and provide their reasons. The three open ended questions were (i) Is learning geometry useful in real life? (ii) Do you have the needed confidence to learn geometry? (iii) Do you enjoy learning geometry? The attitude questionnaire was used to measure the following constructs; usefulness of learning geometry, confidence of learning geometry and enjoyment of learning geometry. The questionnaire contained personal data of the PSTs such as name of college, level, age, programme and gender. The instrument was designed such that higher scores are more indicative of an overall higher attitude toward geometry. Ten (10) items listed from $1-10$ constituted the first construct referred to as usefulness of learning geometry. Twelve (12) items listed from 11-22 constituted the second construct called confidence in learning geometry. The third construct which sort to measure enjoyment of learning geometry consisted of ten (10) items listed from 23-32. The ratio of total sum of the respondents (240) to the total items (32) exceeded the minimum level suggested by Nunnally and Bernstein (1994) and Chua (2009) who stated that the number of respondents should be at least five times more than the number of items. So, in this study, 32 items were used in the study, thus the sample size should be at least 32 multiply by 5 , which produces a minimum sum of 160 . The questionnaire was piloted to 75 PSTs from Yendi and Gambaga Colleges of Education. The purpose of the pilot study was to assist the researchers to identify possible hitches in the study and allows the researchers to revise the instrument before the actual study was conducted

\section{Validity and Reliability}

In order to increase the validity of this study, the 32 -items questionnaire developed by Utley (2007) were first piloted to a similar programme level and age group of pre-service teachers. The questionnaire was vetted and approved by the ethics committee of the University of Education, Winneba. The data generated from the pilot study was used to calculate the Cronbach alpha reliability coefficient. The internal consistency reliability analysis revealed a Cronbach's coefficient alpha of 0.80 for all the three construct which is good for administering. The internal consistency using Cronbach's coefficient alpha was 0.84 for the usefulness subscale, 0.76 for the confidence subscale, and 0.68 for the enjoyment subscale. Also, the overall calculated Cohen's kappa was 0.427 which established moderate agreement of the female and male ratters of the attitude questionnaire items. The 32 item and 3 opened ended attitude questionnaires towards geometry was given to the PSTs to answer within 30 minutes. The closed ended items consisted of positive and negative statements. The questionnaire used a 5-point Likert-type Scale ranging from 1 (strongly disagree) to 5 (strongly agree) to measure the PSTs attitude towards geometry. It contains seventeen (17) positively and fifteen (15) negatively worded questions.

\section{Data Collection Procedure}

For this study, Ethic Committee approval of the instrument was not a requirement. The administration of the instrument was done in the 2019/2020 academic year, first semester from 7th February, 2019 to 14th February, 2019. The PSTs filled the questionnaire within a duration of 30 minutes.

\section{Data Analysis}

Data collected were analysed both qualitatively and quantitatively. Qualitative data were obtained from the open-ended questionnaire items answered by the pre-service teachers. The data were grouped into different categories/themes consistent with the research questions and deduction and generalizations made using patterns and trend of responses. Some responses were also written verbatim to support the themes. In qualitative study, reliability refers to the stability of responses to multiple coders of data sets. To ensure enhanced reliability of this study, detailed field notes by using recording devices and by transcribing the digital files were employed.

Quantitative data were obtained from the questionnaire items answered by the pre-service teachers from the Likert scale. The negatively worded items were recoded before data analysis. Specifically, the data were analysed using independent sample t-test and simple descriptive statistics. The quantitative data met four (4) assumptions (i.e., Independence of the observations, no significant outliers in the two groups, Normality, and Homogeneity of variances (Lund Research Ltd., 2018)) before the independent sample t-test was conducted.

\section{RESULTS}

To support the quantitative analysis, the open-ended statements on usefulness of learning geometry, confidence of learning geometry and enjoyment of learning geometry responses were put into themes and presented with sample opinions from the PSTs in this study.

Research Question 1: What are PSTs' attitudes towards usefulness of learning geometry by gender?

For the female PSTs when they were asked "Is learning geometry useful in real life?" $82.5 \%$ said "yes", 14.2\% said "no" and 3.3\% left it blank. For the questions on whether male PSTs see geometry useful in real life, $87.5 \%$ indicated "yes", $7.5 \%$ responded "no" and $5 \%$ of PSTs left the question blank.

Female PSTs written response / reasons on usefulness of learning geometry

The most common reasons given for female "yes" responses by most respondents were (i) It is useful in solving everyday problems, (ii) It is applicable to everyday life and (iii) To know and identify shape. A response to the usefulness of learning geometry from a PST, when that question was asked is: "Yes, learning geometry is useful in real life because you can as well apply the concept in your everyday life. And when you apply the concept, you have learnt; it can as well help you earn a living". Again, female most common reason for the "no" responses was that, it has no 
Table 1. Percentage response to usefulness of learning geometry

\begin{tabular}{cccc}
\hline Closed Ended Qquestion & Yes & No & Blank \\
\hline "Is learning geometry useful in real life?" & Female= $82.5 \% ;$ Male $=87.5 \%$ & Female= $14.2 \% ;$ Male $=7.5 \%$ & Female $=3.3 \% ;$ Male $=5 \%$ \\
\hline
\end{tabular}

Table 2. Percentage response to confidence of learning geometry

\begin{tabular}{cccc}
\hline Closed Ended Qquestion & Yes & No & Blank \\
\hline "Do you have the needed confidence to learn geometry?" & Female $=47.5 \%$; Male $=73.3 \%$ & Female=44.2\%; Male $=18.3 \%$ & Female $=8.3 \%$; Male $=8.3 \%$ \\
\hline
\end{tabular}

Table 3. Percentage response to enjoyment of learning geometry

\begin{tabular}{cccc}
\hline Closed Ended Qquestion & Yes & No & Blank \\
\hline "Do you enjoy learning geometry?" & Female $=49.2 \%$; Male $=68.3 \%$ & Female $=41.7 \% ;$ Male $=24.2 \%$ & Female $=9.1 \% ;$ Male $=7.5 \%$ \\
\hline
\end{tabular}

link to everyday problems. Below is a captured response from a PST who maintained that, "I do not see any link it has with my future", when the question was asked.

Male PSTs written response/reasons on usefulness of learning geometry

The most common reasons given for the male "yes" answers among majority of the PSTs were as follows; (i) It is useful in solving everyday problems, (ii) it is applicable to everyday life, (iii) promotes critical thinking and (iii) it helps to identify shapes and their properties. A sample response from a PST to the question "Is learning geometry useful in real life?" is: "This is because it helps one to be a critical thinker. It also helps one to be employed at the end of his / her learning programme. It helps to solve everyday problems". On the contrary, the most common male reasons given for the "no" answers by majority of the respondents were (i) It is not useful and (ii) geometry is not applicable in life. Below is a sample response from a PST who maintained that, "I study geometry a lot but I have never applied it somewhere in my life. Rather like the way profit and lost concepts are link to real life situations".

Research Question 2: What are PSTs' attitudes towards confidence of learning geometry by gender?

For the female PSTs when they were asked "Do you have the needed confidence to learn geometry?" For the "yes" and "no" options, 47.5\% responded "yes", $44.2 \%$ ticked "no" and $8.3 \%$ left the question blank. Also, for the male PSTs, 73.3\% responded "yes" $18.3 \%$ ticked "no" and $8.3 \%$ left the question blank or unanswered.

Female PSTs written response / reasons on confidence of learning geometry

For the female PSTs when they were asked "Do you have the needed confidence to learn geometry?" The most common female reasons they advanced for the "yes" option among most participants were (i) I always persevere to learn geometry; (ii) It is a practical subject and (iii) My favorite subject. Below is a response to that question by a PST who maintained "Because I am good in calculations, I have the confidence to learn geometry". Again, most of the female PSTs most common reason for the "no" responses were as follows (i) difficult to understand geometry (ii) I hate it (iii) It is confusing and boring and (iv) Weak foundation. A PST maintained that "Because I am always facing difficulties whenever solving geometric problems, my confidence level is very low".

Male PSTs written response/reasons on confidence of learning geometry

The most common reasons the male PSTs advanced for the "yes" option were (i) easy to understand geometry, (ii) I always persevere to learn geometry, (iii) Because am always motivated to solve geometry problem, (iv) It is fun and interesting and (v) It is practical and based on concrete materials. One PST maintained that, "It is practically oriented, it is sometimes easy to understand. Other concepts are being explained using concrete materials which aid in memory". On the contrary, the male PSTs most common reasons for the "no" responses among majority of the PSTs were (i) difficult to understand geometry and (ii) it is confusing and boring. A sample response from a PST is captured below. "It is sometimes difficult to analyze and apply the methods and rule to solve the geometry".

Research Question 3: What are PSTs' attitude towards enjoyment of learning geometry by gender?

When the female PSTs were asked "Do you enjoy learning geometry?", 49.2\% indicated "yes" 41.7\% responded "no" while 9.1\% abstained from answering the question. For the male PSTs, $68.3 \%$ indicated "yes", $24.2 \%$ responded "no", while $7.5 \%$ abstained from answering the question.

Female PSTs written response / reasons on enjoyment of learning geometry

The most common reasons given by female PSTs for the "yes" option among most respondents were (i) motivated to solve geometry problem, (ii) it improves my critical and logical thinking, (iii) it is practical and (iv) it is fun and interesting. A sample response from a PST when that question was asked is: "When I was introduced to geometry, I immediately developed interest in it because the concepts in it are linked. One concept leads you to another and that makes it enjoyable whenever I am learning it". On the contrary, the most common reasons given by female PSTs for the "no" answer from majority of the participants were as follows; (i) difficult to understand geometry, (ii) it is confusing and boring, and (iii) it is difficult because of so many rules and properties. A captured sample response from a PST stated that, "It is boring and needs a lot of efforts, and this can hinder me from learning other subjects which can result in my failure. I don't even enjoy math in particular".

Male PSTs written response/reasons on enjoyment of learning geometry

The most common male reasons for the "yes" option by majority of the participants were (i) it improves my critical and logical thinking, (ii) easy to understand, (iii) It is fun and interesting, (iv) Because I am always motivated to solve geometry problem and (v) It is Practical and based on concrete materials. A sample response from a PST stated that, "It makes learning interesting and avoid boredom. It is practical". On the contrary, the most common reasons given by male PSTs for the "no" option was (i) difficult to understand geometry and (ii) it is confusing and boring. A sample response from a PST to the question is: "Because I do not always understand the concepts and as a result, I do not develop any interest for it".

From the analysis, both female and male PSTs have some common reasons to the open-ended questions. In conclusion, a wider margin in terms of "yes" answer response percentage was found in the PSTs 
Table 4. Descriptive statistics and independent samples t-test for female and male on usefulness of studying geometry

\begin{tabular}{ccccccccc}
\hline Construct & Group & N & Mean & Sd & Df & T & Sig & Decision \\
\hline \multirow{2}{*}{ Usefulness } & Female & 119 & 3.5 & .79 & 237 & -4.136 & .000 \\
\cline { 2 - 9 } & Male & 120 & 3.9 & .72 & & & \\
\hline
\end{tabular}

Table 5. Independent sample t-test on gender difference on usefulness of learning geometry

\begin{tabular}{|c|c|c|c|c|c|c|c|c|c|}
\hline S/No. & Statement & Sex & $\mathbf{N}$ & Mean & SD & $\mathbf{t}$ & Df & Sig. (2-tailed) & decision \\
\hline \multirow{2}{*}{1} & \multirow{2}{*}{$\begin{array}{l}\text { I believe that I will need geometry for } \\
\text { my future. }\end{array}$} & Female & 119 & 3.65 & 1.23 & \multirow{2}{*}{-1.58} & \multirow{2}{*}{238} & \multirow{2}{*}{.116} & \multirow{2}{*}{ No Difference } \\
\hline & & Male & 120 & 3.90 & 1.23 & & & & \\
\hline \multirow{2}{*}{2} & \multirow{2}{*}{ Geometry has no relevance in my life. } & Female & 118 & 3.74 & 1.13 & \multirow{2}{*}{-3.17} & \multirow{2}{*}{236} & \multirow{2}{*}{.002} & \multirow{2}{*}{ Difference } \\
\hline & & Male & 120 & 4.18 & .99 & & & & \\
\hline \multirow{2}{*}{3} & \multirow{2}{*}{$\begin{array}{c}\text { Geometry is not a practical subject to } \\
\text { study }\end{array}$} & Female & 115 & 3.60 & 1.29 & \multirow{2}{*}{-3.40} & \multirow{2}{*}{221.13} & \multirow{2}{*}{.001} & \multirow{2}{*}{ Difference } \\
\hline & & Male & 118 & 4.12 & 1.05 & & & & \\
\hline \multirow{2}{*}{4} & \multirow{2}{*}{$\begin{array}{l}\text { I can see ways of using geometry } \\
\text { concepts to solve every day problems. }\end{array}$} & Female & 117 & 3.44 & 1.17 & \multirow{2}{*}{-1.28} & \multirow{2}{*}{233} & \multirow{2}{*}{.204} & \multirow{2}{*}{ No Difference } \\
\hline & & Male & 118 & 3.64 & 1.24 & & & & \\
\hline \multirow{2}{*}{5} & \multirow{2}{*}{ Geometry is not worthwhile to study. } & Female & 117 & 3.43 & 1.32 & \multirow{2}{*}{-4.87} & \multirow{2}{*}{209.35} & \multirow{2}{*}{.000} & \multirow{2}{*}{ Difference } \\
\hline & & Male & 119 & 4.15 & .92 & & & & \\
\hline \multirow{2}{*}{6} & \multirow{2}{*}{ I often see geometry in everyday things. } & Female & 118 & 3.16 & 1.31 & \multirow{2}{*}{-3.89} & \multirow{2}{*}{231.23} & 000 & Difforence \\
\hline & & Male & 119 & 3.78 & 1.14 & & & .000 & Dirrerence \\
\hline & I will need a firm understanding of & Female & 118 & 3.51 & 1.23 & & & & \\
\hline 7 & geometry in my future work. & Male & 119 & 3.80 & 1.25 & -1.76 & 235 & .079 & No Difference \\
\hline 8 & I do not expect to use geometry when I & Female & 119 & 3.65 & 1.19 & -273 & 23217 & 007 & Difference \\
\hline 0 & get out of school. & Male & 119 & 4.04 & 1.02 & -2.13 & 202.17 & .007 & Dinterence \\
\hline 0 & 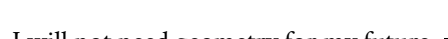 & Female & 118 & 3.46 & 1.23 & 12 & & & \\
\hline 9 & I will not need geometry for my future. & Male & 120 & 4.07 & 1.00 & -4.13 & 225.14 & .000 & Difference \\
\hline 10 & Knowing geometry will help me earn a & Female & 118 & 3.62 & 1.19 & 319 & 236 & 750 & No Difference \\
\hline 10 & living. & Male & 120 & 3.57 & 1.25 & .319 & 236 & .750 & No Difference \\
\hline
\end{tabular}

confidence in learning geometry which was in favour of the male with a percentage difference of $25.8 \%$. Also, $19.1 \%$ was found as a difference in PSTs enjoyment of geometry, again in favour of the male PSTs when the "yes" responses were computed. The usefulness of learning geometry construct was the closets between the gender groups because a difference of $5 \%$ was found between the gender groups "yes" answer responses. In all, the male PSTs showed a positive attitude towards geometry than their female counterparts.

Research Hypotheses 1: Ho: There is no significant difference between female and male PSTs usefulness of studying geometry.

Table 4 presents the independent t-test results of the PSTs attitude towards geometry under the usefulness of learning geometry construct by gender. The data for this analysis was from the 5-point Likert scale responses on usefulness of learning geometry from the PSTs.

Table 4 indicates that there is statistically significant difference between the groups on their perceived usefulness of studying geometry, because $\mathrm{t}(237)=-4.136$ and $\mathrm{p}$-value $=.000<.05$, so we reject the null hypothesis. The t-test result indicates that the male (Mean=3.9; $\mathrm{SD}=0.72)$ thinks positively towards usefulness of studying geometry than their female counterparts with (Mean=3.5; $\mathrm{SD}=0.79$ ). The effect size of the study was calculated to determine the extent of the differences between the male and female groups on usefulness of studying geometry. Detail calculation is shown below

$$
\mathrm{d}=\frac{2 t}{\sqrt{d f}}, \mathrm{~d}=\frac{2(4.136)}{\sqrt{237}}, \mathrm{~d}=\frac{8.272}{15.39}, \mathrm{~d}=0.537
$$

Note: $\mathrm{df}=$ degree of freedom from the Independent Samples T-Test, $\mathrm{t}$ $=\mathrm{t}$-value from the Independent Samples T-Test

The Cohen's $d$ of (0.537) indicates a medium effect size, signifying that $53.7 \%$ of the variance in the PSTs responses on usefulness of geometry favored the Male PSTs.
Table 5 is Independent sample t-test that was employed to determine the particular items on the usefulness of learning geometry construct where the differences came from.

As shown in Table 5, the Independent sample t-test has shown that there were differences in the following item statement numbered 2, 3 , $5,6,8$, and 9 on female and male PSTs responses on usefulness of geometry. The differences favored the male PSTs. However, there was no significant difference in items $1,4,7$, and 10.

Research hypothesis 2 Ho: There is no statistically significant difference between female and male PSTs responses on confidence in learning geometry.

Table 6 presents t-test analysis of PSTs attitude towards geometry under the confidence of learning geometry construct.

From Table 6, the result of the independent samples t-test shows that there is statistical significance difference between female and male PSTs in favor of the male. The female PSTs had $(\mathrm{M}=3.2, \mathrm{SD}=0.67)$ and male $(\mathrm{M}=3.5, \mathrm{SD}=0.58)$ when $(\mathrm{t}(238)=-3.069, \mathrm{p}=.002<.05)$. The result indicates that, the male PSTs have a lot of confidence in learning geometry than their female counterparts. The effect size of the study was calculated to determine the extent of the differences between the male and female groups confidence of learning geometry. Detail calculation is shown below

$$
\begin{aligned}
& \text { Cohen's d }=\frac{M_{2-M_{1}}}{\sqrt{\frac{S D_{1}{ }^{2}+S D_{2}^{2}}{2}}}, \mathrm{~d}=\frac{3.5-3.2}{\sqrt{\frac{(0.67)^{2}+(0.58)^{2}}{2}}}, \mathrm{~d}=\frac{0.3}{\sqrt{\frac{0.4489+0.3364}{2}}}, \mathrm{~d}=\frac{0.3}{\sqrt{\frac{0.7853}{2}}} \\
& \mathrm{~d}=\frac{0.3}{\sqrt{0.39265}} \mathrm{~d}=\frac{0.3}{0.6266}, \mathrm{~d}=0.48 \\
& \text { Note: } \\
& M_{1}=\text { Mean of Female confidence }, M_{2}=\text { Mean of Male confidence, } \\
& S D_{1}=\text { Std.Deviation of Female confidence } S D_{c} \\
& =\text { Std. Deviation of Male confidence }
\end{aligned}
$$


Table 6. Descriptive Statistics and Independent Samples T-Test for Female and Male on their confidence in learning geometry

\begin{tabular}{|c|c|c|c|c|c|c|c|c|}
\hline Construct & Group & $\mathbf{N}$ & Mean & St. Dev & Df & $\mathbf{T}$ & Sig & Decision \\
\hline \multirow{2}{*}{ Confidence } & Female & 120 & 3.2 & .67 & \multirow{2}{*}{238} & \multirow{2}{*}{-3.069} & \multirow{2}{*}{.002} & \multirow{2}{*}{ Difference } \\
\hline & Male & 120 & 3.5 & .58 & & & & \\
\hline
\end{tabular}

Table 7. Independent sample t-test on gender difference on confidence of learning geometry

\begin{tabular}{|c|c|c|c|c|c|c|c|c|c|}
\hline S/No. & Statement & Sex & $\mathbf{N}$ & Mean & SD & $\mathbf{t}$ & Df & $\begin{array}{l}\text { Sig. (2- } \\
\text { tailed) }\end{array}$ & Decision \\
\hline \multirow{2}{*}{11} & \multirow{2}{*}{ I am sure that I can learn geometry concepts. } & Female & 120 & 3.86 & 1.13 & \multirow{2}{*}{-1.011} & \multirow{2}{*}{238} & \multirow{2}{*}{.313} & \multirow{2}{*}{ No difference } \\
\hline & & Male & 119 & 4.00 & 1.04 & & & & \\
\hline \multirow{2}{*}{12} & \multirow{2}{*}{$\begin{array}{l}\text { I often have trouble solving geometry } \\
\text { problems. }\end{array}$} & Female & 120 & 2.53 & 1.25 & \multirow{2}{*}{-1.709} & \multirow{2}{*}{238} & \multirow{2}{*}{.089} & \multirow{2}{*}{ No difference } \\
\hline & & Male & 119 & 2.79 & 1.17 & & & & \\
\hline \multirow{2}{*}{13} & \multirow{2}{*}{$\begin{array}{l}\text { I am confident I can get good grades in } \\
\text { geometry. }\end{array}$} & Female & 120 & 3.68 & 1.15 & \multirow{2}{*}{-1.843} & \multirow{2}{*}{238} & \multirow{2}{*}{.067} & \multirow{2}{*}{ No difference } \\
\hline & & Male & 119 & 3.94 & 1.09 & & & & \\
\hline \multirow[b]{2}{*}{14} & \multirow{2}{*}{$\begin{array}{l}\text { When I cannot figure out a geometry } \\
\text { problem, I feel as though I am lost and cannot } \\
\text { find my way out. }\end{array}$} & Female & 119 & 2.89 & 1.32 & \multirow[b]{2}{*}{.512} & \multirow[b]{2}{*}{236} & \multirow[b]{2}{*}{.609} & \multirow[b]{2}{*}{ No difference } \\
\hline & & Male & 118 & 2.81 & 1.21 & & & & \\
\hline \multirow{2}{*}{15} & \multirow{2}{*}{$\begin{array}{l}\text { I lack confidence in my ability to solve } \\
\text { geometry problems. }\end{array}$} & Female & 119 & 3.08 & 1.36 & \multirow{2}{*}{-2.217} & \multirow{2}{*}{232.538} & \multirow{2}{*}{.028} & \multirow{2}{*}{ difference } \\
\hline & & Male & 118 & 3.45 & 1.21 & & & & \\
\hline \multirow{2}{*}{16} & \multirow{2}{*}{$\begin{array}{l}\text { I feel sure of myself when doing geometry } \\
\text { problems. }\end{array}$} & Female & 120 & 3.27 & 1.18 & & & & difference \\
\hline & & Male & 119 & 3.78 & 1.02 & -3.565 & 233.450 & .000 & airterence \\
\hline 17 & For some reason even though I study, & Female & 119 & 2.75 & 1.15 & -1267 & 237 & 206 & No difference \\
\hline 17 & geometry seems unusually hard for me. & Male & 119 & 2.94 & 1.21 & $-1.26 /$ & 237 & .206 & \\
\hline 18 & Geometry problems often scare me & Female & 116 & 3.19 & 1.36 & -1.015 & 233 & 311 & No difference \\
\hline & & Male & 118 & 3.36 & 1.23 & 13 & & & \\
\hline 19 & I am confident that if I work long enough on a & Female & 120 & 3.88 & 1.16 & 2363 & 238 & 019 & difference \\
\hline 19 & geometry problem, I will be able to solve it. & Male & 120 & 4.21 & 0.96 & -2.363 & 238 & . 019 & \\
\hline 20 & Geometry examinations ucually ceem difficult & Female & 119 & 2.60 & 1.32 & -1850 & 236 & 066 & No difference \\
\hline 20 & Geometry examinations usuanly seem difficuit. & Male & 119 & 2.90 & 1.16 & & & & \\
\hline & & Female & 118 & 3.69 & 1.00 & & & 371 & No difference \\
\hline 21 & I can usually make sense of geometry concepts. & Male & 118 & 3.80 & 0.92 & -.897 & 235 & .371 & No anrerence \\
\hline 22 & I have a lot of confidence when it comes to & Female & 120 & 3.33 & 1.23 & 3007 & & 003 & difference \\
\hline 22 & studying geometry. & Male & 118 & 3.78 & 1.07 & -3.007 & & & \\
\hline
\end{tabular}

Table 8. Descriptive Statistics and Independent Samples T-Test for Female and Male on enjoyment of learning geometry

\begin{tabular}{ccccccccc}
\hline Construct & Group & $\mathbf{N}$ & Mean & Sd & Df & T & Sig & Decision \\
\hline \multirow{2}{*}{ Enjoyment } & Female & 120 & 3.2 & .67 & \multirow{2}{*}{237} & \multirow{2}{*}{-3.105} & \multirow{2}{*}{.002} & \multirow{2}{*}{ Differences } \\
\cline { 2 - 6 } & Male & 119 & 3.5 & .58 & & & & \\
\end{tabular}

The Cohen's $d$ of (0.48) indicates a small effect size, signifying that $48 \%$ of the variance in the PSTs responses on confidence of learning geometry favored the Male PSTs.

Table 7 is Independent sample t-test that was employed to determine the particular items on the confidence of learning geometry construct where the differences came from.

Table 7 displays PSTs responses on their confidence in learning geometry. The Independent sample t-test has confirmed that items numbered 15, 16, 19, and 22 has indicated where differences between the female and male PSTs on their confidence in learning geometry existed. The rest of the items did not reveal differences among the female and male PSTs on their confidence in learning geometry.

Research Hypothesis 2: Ho: There is no statistically significant difference between female and male PSTs responses to enjoyment of learning geometry.

Table 8 presents the descriptive statistics of PSTs attitude towards geometry under the enjoyment of learning geometry construct.

Table 8 depicts the independent samples t-test of both female and male PSTs on their responses to enjoyment of learning geometry. From Table 8, there is statistically significant difference between the groups on their perceived responses to enjoyment of learning geometry, because $t(237)=-3.105$ and $\mathrm{p}$-value $=.002<.05$ with male $($ Mean $=3.5$; $\mathrm{SD}=.58)$. It means the male PSTs enjoys learning geometry than their female counterparts with (Mean=3.2; $\mathrm{SD}=.67$ ). The effect size of the study was calculated to determine the extent of the differences between the male and female groups on enjoyment of learning geometry. Detail calculation is shown below.

$$
\mathrm{d}=\frac{2 t}{\sqrt{d f}}, \mathrm{~d}=\frac{2(3.105)}{\sqrt{237}}, \mathrm{~d}=\frac{6.21}{15.39}, \mathrm{~d}=0.403 .
$$

Note: $\mathrm{df}=$ degree of freedom from the Independent Samples T-Test, $\mathrm{t}$ $=\mathrm{t}$-value from the Independent Samples T-Test

The Cohen $d$ of (0.403) indicates a small effect size, signifying that $40.3 \%$ of the variance in the PSTs responses enjoys learning geometry favored the Male PSTs.

Table 9 is independent samples t-test that was employed to determine the particular items on enjoyment of learning geometry construct where the differences came from.

It is clear from Table 9 that, some differences exist between the female and male PSTs on the issue of whether they enjoy learning geometry from the independent samples t-test. The items that show the 
Table 9. Independent sample t-test on gender difference on enjoyment of learning geometry

\begin{tabular}{|c|c|c|c|c|c|c|c|c|c|}
\hline S/No. & Statement & Sex & $\mathbf{N}$ & Mean & SD & $\mathbf{t}$ & Df & Sig. (2-tailed) & Decision \\
\hline \multirow{2}{*}{23} & \multirow{2}{*}{ Geometry problems are boring. } & Female & 120 & 3.29 & 1.20 & \multirow{2}{*}{-1.59} & \multirow{2}{*}{235} & \multirow{2}{*}{.113} & \multirow{2}{*}{ No Difference } \\
\hline & & Male & 119 & 3.53 & 1.20 & & & & \\
\hline \multirow{2}{*}{24} & \multirow{2}{*}{$\begin{array}{l}\text { When I leave class with a geometry question } \\
\text { unanswered, I continue to think about it. }\end{array}$} & Female & 117 & 3.69 & 1.13 & \multirow{2}{*}{-1.03} & \multirow{2}{*}{232.92} & \multirow{2}{*}{.302} & \multirow{2}{*}{ No Difference } \\
\hline & & Male & 119 & 3.83 & 1.00 & & & & \\
\hline \multirow{2}{*}{25} & \multirow{2}{*}{$\begin{array}{l}\text { When I start solving a geometry problem, I } \\
\text { find it hard to stop working on it. }\end{array}$} & Female & 118 & 3.10 & 1.23 & \multirow{2}{*}{-1.19} & \multirow{2}{*}{237} & \multirow{2}{*}{.235} & \multirow{2}{*}{ No Difference } \\
\hline & & Male & 119 & 3.29 & 1.18 & & & & \\
\hline 26 & Time drags during geometry class. & Male & 119 & 2.82 & 1.14 & -0.40 & 235 & .693 & No Difference \\
\hline \multirow{2}{*}{27} & \multirow{2}{*}{ Geometry is fun. } & Female & 118 & 2.92 & 1.36 & \multirow{2}{*}{-1.19} & \multirow{2}{*}{236} & \multirow{2}{*}{.234} & \multirow{2}{*}{ Difference } \\
\hline & & Male & 119 & 3.12 & 1.24 & & & & \\
\hline \multirow{2}{*}{28} & \multirow{2}{*}{$\begin{array}{l}\text { I just try to get my homework done for } \\
\text { geometry class in order to get a grade. }\end{array}$} & Female & 117 & 2.33 & 1.09 & \multirow{2}{*}{-1.54} & \multirow{2}{*}{236} & 124 & Difference \\
\hline & & Male & 119 & 2.55 & 1.18 & & & .124 & Dinterente \\
\hline 20 & 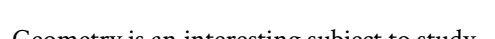 & Female & 114 & 3.53 & 1.23 & A6 & 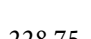 & 015 & Difforonce \\
\hline 29 & Geometry is an interesting subject to stuay. & Male & 119 & 3.91 & 1.10 & -2.46 & 248.15 & .015 & Difference \\
\hline 30 & Solying coometry problems is oniouble & Female & 117 & 3.31 & 1.29 & 262 & 23120 & 009 & Difference \\
\hline 30 & sorving geometry prodiems is enjoyade. & Male & 119 & 3.72 & 1.12 & -2.03 & 231.22 & .009 & Dirrerence \\
\hline 31 & Working out geometry problems does not & Female & 118 & 3.04 & 1.28 & 35 & 22810 & 001 & Difference \\
\hline 31 & appeal to me. & Male & 119 & 3.55 & 1.04 & -3.35 & 228.19 & .001 & Dirrerence \\
\hline 32 & Geometry has many interesting topics to & Female & 118 & 3.59 & 1.18 & 73 & 23128 & 007 & Diff $f_{\epsilon}$ \\
\hline 32 & study. & Male & 119 & 3.98 & 0.99 & -2.13 & 231.28 & .007 & Difference \\
\hline
\end{tabular}

Table 10. Descriptive Statistics and Independent Samples T-Test for Female and Male on their attitude towards geometry

\begin{tabular}{|c|c|c|c|c|c|c|c|c|}
\hline Construct & Group & $\mathbf{N}$ & Mean & Sd & df & $\mathrm{T}$ & Sig & Decision \\
\hline \multirow{2}{*}{ Attitude } & Female & 120 & 3.3 & .57 & \multirow{2}{*}{238} & \multirow{2}{*}{-4.443} & \multirow{2}{*}{.000} & \multirow{2}{*}{ Differences } \\
\hline & Male & 120 & 3.6 & .50 & & & & \\
\hline
\end{tabular}

differences between the female and male PSTs are 27, 28, 29, 30, 31 and 32 .

Research Hypothesis 4: Ho: There is no statistically significant difference between female and male PSTs responses on attitude towards geometry with usefulness, confidence and enjoyment of geometry all combined.

Table 10 presents the descriptive statistics of PSTs attitude towards geometry. The overall attitude hypothesis is been tested to ascertain the differences between gender.

Table 10 displays the independent samples t-test of both female and male PSTs on their responses from the 5-point Likert scale on attitude towards studying geometry. From the results, it was revealed that there is statistically significant difference between the female and male PSTs on their attitude towards studying geometry, because the independent sample $\mathrm{t}$-test has reported the following $\mathrm{t}(238)=-4.443$ and $\mathrm{p}$-value $=$ $.000<.05$, so we reject the null hypothesis that there is no significant difference between female and male PSTs attitude towards geometry. The effect size of the study was calculated to determine the extent of the differences between the male and female groups overall attitude (usefulness, confidence and enjoyment) towards geometry. Detail calculation is shown below.

$$
\begin{gathered}
\text { Cohen's } \mathbf{d}=\frac{M_{2-} M_{1}}{\sqrt{\frac{S D_{1}^{2}+S D_{2}^{2}}{2}}}, \mathrm{~d}=\frac{3.6-3.3}{\sqrt{\frac{(0.57)^{2}+(0.50)^{2}}{2}}}, \mathrm{~d}=\frac{0.3}{\sqrt{\frac{0.3249+0.25}{2}}}, \mathrm{~d}=\frac{0.3}{\sqrt{\frac{0.5749}{2}}}, \\
\mathrm{~d}=\frac{0.3}{\sqrt{0.28745}}, \mathrm{~d}=\frac{0.3}{0.533}, \mathrm{~d}=0.56 \\
\text { Note: } M_{1}=\text { Mean of Female attitude }, M_{2}=\text { Mean of Male attitude } \\
S D_{1}=\text { Std. Deviation of Female attitude } S D_{c} \\
=\text { Std. Deviation of Male attitude }
\end{gathered}
$$

The Cohen $\mathrm{d}$ of (0.56) indicates a medium effect size, signifying that $56 \%$ of the variance in the PSTs responses on their attitude towards geometry favored the Male PSTs.

\section{DISCUSSION OF RESULTS}

From the qualitative analysis, majority (82.5\%) of the female PSTs indicated that geometry is useful in real life. Most of them said it is useful in solving everyday problem. The solving of everyday problems enables students to develop the skills of visualization, critical thinking, intuition, perspective, problem-solving, conjecturing, deductive reasoning, logical argument and proof which support Armah et al. (2017) findings. Again, majority of the PSTs said geometry will be needed in their future work which also corroborates with studies of Sunzuma et al. (2013) where they found that geometry is used daily by architects, engineers, physicists, land surveyors and many more professions. While majority (87.5\%) of the male PSTs said geometry was useful in solving everyday problems in real life, which is in line with Armah et al. (2017) findings where they argued that in solving everyday problem with geometry, PSTs develop the skills of visualization, critical thinking, intuition, perspective, problem-solving, conjecturing, deductive reasoning, logical argument and proof. On the contrary, some of female preservice teachers said it has no link to everyday problems which differs from the findings of Van de Walle (2001) who found that geometry is linked to structure of the solar system art, architecture, cars, machines, geometric explorations, building a fence, designing a house and planning a garden. Some male PSTs indicated that geometry is not useful in real life.

On the sub-construct of Confidence, almost half (47.5\%) of the total number of the female PSTs have acknowledged that they have confidence in learning geometry, whereas majority (73.3\%) of male PSTs said they have confidence in learning geometry because geometry is easy to understand. This study tallies with Niyukuri, Nzotungicimpaye and Ntahomvukiye (2020) who found that Pre- 
service Teachers displayed higher confidence in teaching geometry. However, some of the male PSTs had a contrary opinion that geometry is difficult. Confidence is very significant in learning mathematics because it enables students to be sure of themselves when solving nonroutine problems on their own especially studying new concepts. Confidence affects students' enjoyment, interest and involvement in mathematics. It is good to see almost half of the female showing confidences in geometry because it is perceived to be the most difficult mathematics course in Colleges of Education in Ghana. Some of the female PSTs opined that, they always persevere to learn geometry because of the self-confidence they have. This confidence can emanate from the classroom teacher who uses learner centered approach. Those students who concluded that geometry is difficult to understand might have not received confidence boosting from their teachers in the past. Gresham (2017) agrees with this study because it was revealed that low level of confidence results in pre-service teachers choosing to teach at a lower grade schools or classes.

For the enjoyment sub-construct, some (49.2\%) of the female PSTs indicated that geometry is fun and interesting because their teachers might be using real and concrete objects in delivering the lessons or the use of mathematics software to make teaching of geometry fun and interesting. This assertion that geometry is fun and interesting is similar to Kyei et al. (2011) which found that, students' interest in mathematics was inclined to personal interest and teaching methods of teachers. Whereas majority (68.3\%) of the male PSTs said they enjoy learning geometry because it improves their critical and logical thinking. This assertion agrees with Armah et al. (2017) study where they found that learning geometry improves skills of visualization, critical thinking, intuition, perspective, problem-solving, conjecturing, deductive reasoning, logical argument and proof. On the contrary, some of the female PSTs said they do not enjoy geometry because it confusing and boring. This could be attributed to the way teachers present geometry lesson by making students to memorize formulas through rote learning. This suggests that if female PSTs are given equal opportunity by tutors in the classroom their confidence could be raised to make them enjoy geometry lessons. Whereas some male PSTs said geometry is difficult to understand.

From the independent sample t-test, there is statistically significant difference between the groups on their perceived usefulness of studying geometry. This study has revealed that PSTs attitude towards the usefulness of learning geometry was positive and that many of them believed that geometry is a valuable and necessary topic which can help them in their future teaching. The findings of this study are similar to Awofala (2016) who also indicated that preservice teachers' attitudes towards mathematics were positive and high. Russo et al. (2020) study corroborates with this finding because their study concluded that earlyyear primary school teachers have positive feelings towards mathematics. This finding is similar to the findings of YoungLoveridge et al. (2006) which indicated that students see usefulness of mathematics as a major factor for their daily life and future career formation. This finding also tallies with Sunzuma et al. (2013) who found that students considered geometry to be useful. From this study, the mean difference recorded was in favour of males suggesting that male PSTs see geometry very useful than their female counterparts. From the analysis, significant differences exist between the female and male PSTs on their confidence in learning geometry and it was in favour of the Male PSTs. This supports the findings of Asante (2010) who affirmed that girls lacked confidence, and perceived Mathematics as a male domain. This finding also corroborates with Bae et al. (2000) study which revealed that females are less likely than males to think they are good at mathematics. Again, to support this assertion, Cann (2009) reported that Wales girls were more likely than boys to report feelings of anxiety and a lack of confidence in mathematics. Further analysis from the PSTs responses on whether they enjoy learning geometry also indicated a significant difference in favour of male PSTs.

In conclusion, when the overall t-test was conducted for all the constructs there was statistically significant difference among the groups in their attitude towards geometry in favour of the male PSTs. This study is similar to Asante (2012), Michelli (2013), Sunzuma et al. (2013), Simegn and Asfaw (2018), and Tasdemir (2009) where they all found that, male students have more positive attitude than their female counterparts. The findings of this study differ from that of Awofala (2016) discloses that there was no significant difference by gender, selfconfidence, enjoyment, motivation, and value of mathematics. Also, this study is direct opposite to the findings of Carroll and Gill (2011) where most female students had considerable positive attitudes towards mathematics than their male counterparts.

\section{IMPLICATIONS OF THE STUDY}

This study indicated that some female and male PSTs do not see the usefulness of geometry outside the classroom which means that tutors of Colleges of Education are likely not to be linking geometry to real life situations when teaching geometry concepts. Hence, if these PSTs complete their programme they are likely to be teaching geometry without relating it to real life because they do not recognize the usefulness of geometry in life. Such PSTs might be skipping some geometry concepts. This might explain why students fail geometry when questions are presented in real life situation or in application format. The researchers will encourage female and male tutors to always give real life practical questions to PSTs to solve in order to eliminate the perception that geometry is not useful after school. Also, some female and male PSTs do not have confidence in learning geometry which also contribute to their failure because they indicated that it is difficult to understand and boring. These PSTs are likely going to discourage their students in learning mathematics at the basic school level which will results in failures in mathematics. Without the needed confidence in class by the female and male PSTs, not paying attention to tutors' lesson will result in poor performance.

\section{CONCLUSION}

Based on the findings made in this study, it can be concluded that:

1. The male PSTs think positively towards usefulness of studying geometry than their female counterparts.

2. The male PSTs have more confidence than their female counterparts on confidence in learning geometry.

3. More male PSTs enjoy learning geometry than their female counterparts.

4. Overall attitude towards geometry revealed that males had shown more positive attitude towards geometry than their female counterparts.

5. There was statistically significant difference in attitude towards geometry in all the constructs and it favoured the male PSTs. 


\section{RECOMMENDATIONS}

From the findings of this study, it is recommended that:

1. College Tutors should consider gender issue seriously when teaching geometry because of the gap between female and male PSTs attitude towards geometry in this study.

2. On the issue of the usefulness of geometry, tutors should present geometry concepts practically by relating it to real life situations to ensure parity in attitude towards geometry by gender.

3. Tutors should also develop PSTs confidence in learning geometry by constantly motivating and encouraging both genders to persevere to work more examples on their own to ensure parity in attitude towards geometry by gender.

4. Tutors should also encourage PSTs to watch online videos of geometry concepts to enhance their enjoyment.

5. Curriculum developers should include innovative strategies or practical activities in the syllabus and textbooks to build PSTs confidence and make geometry lessons enjoyable to bridge the gender differences in attitude towards geometry.

\section{RECOMMENDATIONS FOR FUTURE RESEARCHERS}

The educational implication of the findings of this study calls for further research involving Pre-Service Teachers' Attitude towards Geometry by Gender in Ghana. The following are suggested for further research:

1. Similar studies should be conducted in Southern Ghana Colleges of Education.

2. Other attitude scales aside usefulness, confidence and enjoyment of geometry should be considered in future studies.

3. A follow-up study be conducted on the same PSTs to determine the change in their attitude towards geometry, precisely on the constructs of usefulness, confidence and enjoyment of geometry.

4. Similar study using the same constructs should be research into by determining the correlation between the constructs (usefulness, confidence and enjoyment) of geometry.

\section{LIMITATIONS OF THE STUDY}

This study will add significant value to the existing knowledge on PSTs attitude (usefulness, confidence, and enjoyment) towards Geometry by Gender. However, the results of this study should be interpreted with caution because of the limitation in the research design used. It has been stated in literature that survey researches use selfreported data without any proof of the authenticity of respondents' views. In this study PSTs explained their own experience and opinion subjectively with regards to their understandings of usefulness, confidence and enjoyment towards Geometry. Their status as PSTs might have influenced them to show positive feelings on; usefulness, confidence and enjoyment towards Geometry and given the fact they are been trained to teach geometry in the Ghanaian basic schools. Also, the open-ended attitude towards geometry questionnaire given to the
PSTs was an attempt to reduce the effect of guessing the yes and no options. PSTs were expected to supply reasons for their choice but a few PSTs did not supply reasons for their yes/no answers. Lastly, out of the 46 Colleges of Education in Ghana, only 3 were sampled for this study which has restricted the scope of this study. Hence, the findings of this study cannot be generalized to all PSTs in Ghana.

Author contributions: All authors were involved in concept, design, collection of data, interpretation, writing, and critically revising the article. All authors approve final version of the article.

Funding: The authors received no financial support for the research and/or authorship of this article.

Declaration of in terest: Authors declare no competing interest.

Data availability: Data generated or analysed during this study are available from the authors on request.

\section{REFERENCES}

Adelson, J. L., \& McCoach, D. B. (2011). Development and psychometric properties of the math and me survey: Measuring third through sixth graders' attitudes toward mathematics. Measurement and Evaluation in Counselling and Development, 44(4), 225-247. https://doi.org/10.1177/0748175611418522

Armah, R. B., Cofie, P. O., \& Okpoti, C. A. (2017). The geometric thinking levels of pre-service teachers in Ghana. Higher Education Research, 2(3), 98-106. https://www.researchgate.net/publication/ 319044016_The_Geometric_Thinking_Levels_of_Pre-service_ Teachers_in_Ghana

Asante, K. O. (2010). Sex differences in mathematics performance among senior high Students in Ghana. https://doi.org/10.4314/ gab.v8i2.61947

Asante, K. O. (2012). Secondary students' attitudes towards mathematics. IFE PsychologIA, 20(1), 121-133. http://www.ajol.info /index.php/ifep/article/view/74705

Asare-Nkoom, S. (2007) Sex-differences in attitudes towards mathematics of junior secondary school pupils in the central Region of Ghana. African Journal of Educational Studies in Mathematics and Sciences, 5(1), 21-27. https://doi.org/10.4314/ajesms.v5i1.38610

Asomah, R. K., Dennis, H., Alhassan, M. N., \& Aseidu, K. J. (2018). Ghanaian public and private junior high school mathematics classroom learning environment: A look at students' attitudes. African Journal of Educational Studies in Mathematics and Sciences, 14, 199-200. https://doi.org/10.4314/ajesms.v14i1

Atanasova-Pachemska, T., Lazarova, L., Arsov, J., Pacemska, S., \& Trifunov, Z. (2015). Determination of the factors that form the students' attitude towards mathematics. Mathematics Education Research (MER), 8(12), 1-8. http://eprints.ugd.edu.mk/12056/

Awofala, A. O. A (2016). Examining preservice mathematics teachers attitudes toward mathematics. Nigerian Journal of Curriculum Studies, 23, 292-300.

Awofala, A. O., Arigbabu, A. A., \& Awofala, A. A. (2013). Effects of framing and team assisted individualised instructional strategies on senior secondary school students' attitudes toward mathematics. Acta Didactica Napocensia, 6(1), 1. 
Bae, Y., Choy, S., Geddes, C., Sabble, J., \& Snyder, T. (2000). Trends in educational equity of girls and women. Education Statistics Quarterly, 2(2), 115-120. https://nces.ed.gov/pubs2000/2000030.pdf

Ball, D. L. (1990). Pre-service elementary and secondary teachers' understanding of division. Journal for Research in Mathematics Education, 21(2), 132-144. https://doi.org/10.5951/jresematheduc. 21.2.0132

Cann, R. (2009). Girls' participation in post-16 mathematics: A view from pupils in Wales. Gender and Education, 21(6), 651-669. https://doi.org/10.1080/09540250802680065

Carroll, C., \& Gill, O. (2012). Teaching mathematics and its applications. An International Journal of IMA, 31(4), 199-214. https://doi.org/10.1093/teamat/hrs008

Cavallo, A. M. L., \& Laubach. T. A. (2001). Students' science perceptions and enrollment decisions in differing learning cycle classrooms. Journal of Research in Science Teaching, 38(9), 1029-1062. https://doi.org/10.1002/tea.1046

Chua, Y. P. (2009). Advanced research statistics: Regression test, factor analysis and SEM analysis. McGraw-Hill Education.

Dede, Y. (2012). Students' attitudes towards geometry: a cross-sectional study. International Journal for Studies in Mathematics Education, 5(1), 85-113. https://doi.org/10.17921/2176-5634.2012v5n1p\%25p

Erdogan, T., Akkaya, R., \& Akkaya, S. C. (2009). The effect of the Van Hiele model based instruction on the creative thinking levels of 6th grade primary school students. Educational Sciences: Theory and Practice, 9(1), 181-194. https://www.semanticscholar.org/paper/ Eff-ect-of-the-Van-Hiele-Model-Based-Instruction-on-Erdo\%C4 \%9Fan-Akkaya/f68c76979ecbed6f1489d5ae2d4c635753b3db1e

Eshun, B. A. (2004). Sex-differences in attitude of students towards mathematics in secondary schools. Mathematics Connection, 4, 1-13. https://doi.org/10.4314/mc.v4i1.21495

Frenzel, A. C., Fiedler, D., Marx, A. K. G., Reck, C., \& Pekrun, R. (2020). Who enjoys teaching, and when? Between-and withinperson evidence on teachers' appraisal-emotion links. Frontiers in Psychology, 11. https://doi.org/10.3389/fpsyg.2020.01092

Goos, M., \& Spencer, T. (2003). Properties of shape, mathematicsmaking waves. In M. Goos \& T. Spencer (Eds.), Proceedings of the 19th biennial conference of the Australian association of mathematics teachers (pp. 424-434). AAMT Inc.

Gresham, G. (2017). Preservice to inservice: Does mathematics anxiety change with teaching experience? Journal of Teacher Education, 1-18. https://doi.org/10.1177/0022487117702580

Guner, N. (2012). Using metaphor Analysis to explore High School students' Attitudes towards learning mathematics. Education, 133(1), 39-48.

Hannafin, R. D. (2004). Achievement differences in structured versus unstructured instructional geometry programs. Educational Technology Research and Development, 52(1),19-32. https://doi.org/10.1007/BF02504770

Hannafin, R. D., Truxaw, M. P., Vermillion, J. R., \& Liu, Y. J. (2008). Effects of spatial ability and instructional program on geometry achievement. Journal of Educational Research, 101(3), 148-156. https://doi.org/10.3200/JOER.101.3.148-157
Hannula, S. M., Maijala, H., \& Pehkonen, E. (2004). Developing understanding and self-confidence in mathematics; Grades 5-8. Proceedings of the 28th Conference of the International Group for the Psychology of Mathematics Education.

Hart, L., \& Walker, J. (1993). Research ideas for the classroom: Middle grades mathematics. Macmillan Publishing Company.

Kadijevich, D. (2006). Developing trustworthy TIMSS background measures: A case study on mathematics attitude. The Teaching of Mathematics, 9(2), 41-51.

Karjanto, N. (2017). Attitude toward mathematics among the students at Nazarbayev University Foundation Year Programme. International Journal of Mathematical Education in Science and Technology, 48(6), 849-863. https://doi.org/10.1080/0020739X. 2017.1285060

Kaufmann, H., \& Schmalstieg, D. (2003). Mathematics and geometry education with collaborative augmented reality. Computers $\&$ Graphics - UK, 27(3), 339-345. https://doi.org/10.1016/S00978493(03)00028-1

Kaur, K. (2016). Achievement in mathematics of ninth class government school students in relation to their attitude towards mathematics. International Journal of Informative \& Futuristic Research, 3(6), 2020-2027. http://ijifr.com/searchjournal.aspx

Khun-Inkeeree, H., Omar-Fauzee, M. S., \& Haji-Othman, M. K. (2016). Students' attitude towards achievement in mathematics: a cross sectional study of year six students in songklha province, Thailand. European Journal of Education Studies, 2(4), 89-99.

Knezek, G. A. \& Christensen, R. (2018). Learner attributes and technology-enriched environments associated with positive climate change attitudes and energy and environmental science knowledge in middle school students. In T. Bastiaens, J. Van Braak, M. Brown, L. Cantoni, M. Castro, R. Christensen, G. DavidsonShivers, K. DePryck, M. Ebner, M. Fominykh, C. Fulford, S. Hatzipanagos, G. Knezek, K. Kreijns, G. Marks, E. Sointu, E. Korsgaard Sorensen, J. Viteli, J. Voogt, P. Weber, E. Weippl \& O. Zawacki-Richter (Eds.), Proceedings of EdMedia: World Conference on Educational Media and Technology (pp. 1736-1743). Association for the Advancement of Computing in Education (AACE). Retrieved May 25, 2021 from https://www.learntechlib.org/primary/p/ 184403/

Kupari, P., \& Nissinen, K. (2013). Background factors behind mathematics achievement in Finnish education context: Explanatory models based on TIMSS 1999 and TIMSS 2011 data. IEA CONFERENCE 2013, Proceedings. https://www.iea.nl/fileadmin /user_upload/IRC/IRC_2013/Papers/IRC2013_Kupari_Nissinen. pdf

Kyei, L., Apam, B., \& Nokoe, K. S. (2011). Some gender differences in performance in senior high mathematics examinations in mixed high schools. American journal of social and management sciences, 2(4), 348-355. https://doi.org/10.5251/ajsms.2011.2.4.348.355

Li, Y., \& Kulm, A.E. G. (2008). Knowledge and confidence of preservice mathematics teachers: the case of fraction division. ZDM, 40, 833-843. https://doi.org/10.1007/s11858-008-0148-2

Lund Research Ltd. (2018). Independent t-test using SPSS statistics. https://statistics.laerd.com/spss-tutorials/independent-t-testusing-spss-statistics.php 
Marbán, J. M., Palacios, A., \& Maroto, A. (2020). Enjoyment of teaching mathematics among pre-service teachers. Mathematics Education Research Journal. https://doi.org/10.1007/s13394-020-00341-y

Markovits, Z., \& Patkin, D. (2021). Preschool in-service teachers and geometry: Attitudes, beliefs and knowledge. International Electronic Journal of Mathematics Education, 16(1), em0619. https://doi.org/10.29333/iejme/9303

Mata, M., de Lourdes Monteiro V., \& Peixoto, F. (2012). Attitudes towards mathematics: Effects of individual, motivational, and social support factors. Child Development Research, 34, 1149-041. https://doi.org/10.1155/2012/876028

Mato, M., \& De la Torre, E. (2010). Assessment of attitudes towards mathematics and academic performance. In M. J. González, M. T. González, \& J. Murillo (Eds.), Investigación en educación matemática [Research in mathematics education] (pp. 285-300, Vol. 13). SEIEM.

Mensah, J. K., Okyere, M., \& Kuranchie, A. (2013). Student Attitude towards Mathematics and Performance: Does the Teacher Attitude Matter? Journal of Education and Practice, 4(3), 132-139. https:// www.iiste.org/Journals/index.php/JEP/article/view/4502/4570

Michelli, M. (2013). The relationship between attitudes and achievement in mathematics among fifth grade students (Honors Thesis). Paper 126. http://aquila.usm.edu/cgi/viewcontent.cgi?article=1162\&context =honors_theses

Mistretta, R. M. (2000). Enhancing geometric reasoning. Adolescence, 35(138), 365-379.

Mohamed, L., \& Waheed, H. (2011). Secondary students' attitude towards mathematics in a selected school of Maldives. International journal of Humanities and Social Science, 1(15 Special Issue)), 277-281.

National Council of Teachers of Mathematics (NCTM). (1989). Curriculum and evaluation standards for school mathematics.

Niyukuri, F., Nzotungicimpaye, J., \& Ntahomvukiye, C. (2020). Preservice teachers' secondary school experiences in learning geometry and their confidence to teach it. EURASIA Journal of Mathematics, Science and Technology Education, 16(8), em1871 https://doi.org/10.29333/ejmste/8334

Nunnally, J. C., \& Bernstein, I. H. (1994). Psychometric theory (3rd ed.). Mc Graw-Hill.

Nyala, J. I. (2008). Sex- difference in attitude towards mathematics of Junior high school students in Ghana. Edo Journal of Counselling, 1(1), 137-161. https://doi.org/10.4314/ejc.v1i1.52397

OECD. (2013). Students' drive and motivation. Results: Ready to learnstudents' engagement, drive and self-beliefs. Volume III. OECD. https://doi.org/10.1787/9789264201170-7-en

Özgün-Koca, S. A., \& Şen, A. İ. (2006). The reasons of secondary education students' mathematics and science lessons for negative attitudes. Eurasian Journal of Educational Research, 23, 137-147.

Pekrun, R. (2006). The control-value theory of achievement emotions: assumptions, corollaries, and implications for educational research and practice. Educational Psychology Review, 18(4), 315e341. https://doi.org/10.1007/s10648-006-9029-9

Russo, J. A., \& Russo, T. (2019). Teacher interest-led inquiry: unlocking teacher passion to enhance student learning experiences in primary mathematics. International Electronic Journal of Mathematics Education, 14(3), 701e717. https://doi.org/10.29333/iejme/5843
Russo, J., Bobis, J., Downton, A., Feng, M., Hughes, S., Livy, S., McCormick, M., \& Sullivan, P. (2021) Characteristics of high enjoyment teachers of mathematics in primary schools. Mathematics Education Research Journal. https://doi.org/10.1007/s13394-02100372-z

Russo, J., Bobis, J., Sullivan, P., Downton, A., Livy, S., McCormick, M., \& Hughes, S. (2020). Exploring the relationship between teacher enjoyment of mathematics, their attitudes towards student struggle and instructional time amongst early years primary teachers. Teaching and Teacher Education, 88, 102983. https://doi.org/10.1016/j.tate.2019.102983

Simegn, E. M., \& Asfaw, Z. G. (2018). Assessing the influence of attitude towards mathematics on achievement of grade 10 and 12 female students in comparison with their male counterparts: Wolkite, Ethiopia. International Journal of secondary education, 5(5), 56. https://doi.org/10.11648/j.ijsedu.20170505.11

Stipek, D. (2002). Good instruction is motivating. In A. Wigfield \& J. S. Eccles (Eds.), Development of achievement motivation (pp. 309-332). Academic Press. https://doi.org/10.1016/B978-0127500539/50014-0

Sunzuma, G., Masocha, M., \& Zezekwa, N. (2013). Secondary school students' attitudes towards their learning of geometry: a survey of bindura urban secondary schools. Greener Journal of educational Research, 3(8), 402-410. https://doi.org/10.15580/GJER.2013. 8.051513614

Syyeda, F. (2016). Understanding attitudes towards mathematics (ATM) using a multimodal modal model: An exploratory case study with secondary school children in England. Cambridge Open-Review Educational Research e-Journal, 3, 32-62. http://corerj.soc.srcf.net/ ?page_id=224

Tapia, M., \& Marsh, G. E. (2004). An instrument to measure mathematics attitudes. Academic Exchange Quarterly, 8(2), 16-22.

Taşdemir, C. (2009). Primary school second level students' attitudes towards mathematics course: The example of Bitlis province. Journal of Dicle University Ziya Gökalp Education Faculty, 12, 89-96.

Tsao, Y. L. (2017). Pre-service elementary school teachers' attitude towards geometry. US-China Education Review B, 7(1), 15-22. https://doi.org/10.17265/2161-6248/2017.01.002

Tsao, Y. L. (2018). The Effect of Constructivist Instructional-Based Mathematics Course on the Attitude Toward Geometry of PreService Elementary School Teachers. US-China Education Review A, 8(1), 1-10. https://doi.org/10.17265/2161-623X/2018.1.001

Usman, H., Yew, W. T., \& Saleh, S. (2019). Effects of van Hiele's phasebased teaching strategy and gender on pre-service mathematics teachers' attitude towards geometry in Niger State, Nigeria. African Journal of Educational Studies in Mathematics and Sciences, 15, 61-75. https://doi.org/10.4314/ajesms.v15i1.6

Utley, J. (2007). Construction and validity of geometry attitude scales. School Science and Mathematics, 107(3), 89-93. https://doi.org/ 10.1111/j.1949-8594.2007.tb17774.x

Van de Walle, J. A. (2001). Geometric thinking and geometric concepts. In Elementary and middle school mathematics: teaching developmentally (4th Ed.). Allyn and Bacon. 
Van der Bergh, E. (2013). The influence of academic self-confidence on mathematics achievement (Doctoral dissertation), North-West University.

Wigfield, A., \& Eccles, J. S. (2002). The development of competence beliefs, expectancies for success, and achievement values from childhood through adolescence. In A. Wigfield \& J. S. Eccles (Eds.), Development of achievement motivation (pp. 92-122). Academic Press. https://doi.org/10.1016/B978-012750053-9/50006-1

Wilmot, E. M., \& Otchey, J. E. (2012). The contribution of attitudes of students and teachers to junior high school students' achievement in mathematics. African Journal of Educational Studies in Mathematics and Sciences, 10, 55-63.
Winter, E., \& O'Raw, P. (2010). Literature review of the principles and practice relating to inclusive education for children with special needs. The National Council for Special Education funded this report. https://www.researchgate.net/publication/319482978_Literature _Review_of_the_Principles_and_Practices_relating_to_Inclusive_ Education_for_Children_with_Special_Educational_Needs_The_ National_Council_for_Special_Education_was_established_under _the_Educa

Young-Loveridge, J., Taylor, M., Sharma, S., \& Hawera, N. (2006). Students' perspectives on the nature of mathematics. In F. Ell et al. (Eds.), Findings from the New Zealand Numeracy Development Projects 2005 (pp. 55-64). Ministry of Education.

Zan, R., \& Di Martino, P. (2007). Attitude toward mathematics: Overcoming the positive/negative dichotomy. The Montana Mathematics Enthusiast, Monograph, 3, 157-168. 